\title{
Endless Hours: Is It Fair?
}

\author{
Mukesh Sanklecha ${ }^{1}$
}

Received: 15 July 2015 / Accepted: 12 August 2015 /Published online: 19 September 2015

(C) Dr. K C Chaudhuri Foundation 2015

These words were coined by me just after finishing my pediatric residency in K.E.M. Mumbai and joining L.T.M.M.C. as a lecturer in 1992. A piece that I wrote from the bottom of my heart but never got down to publishing. When I see the conditions of residents today, I strongly feel that the words are as relevant today as they were in 1992.

To the Editor: Seeing the junior residents working in the wards and intensive care units reminds me of my own days as a junior resident. What such a resident goes through is truly deplorable and unfortunate. On an average, a junior resident who is on call every alternate day (as is common) works approximately $115 \mathrm{~h}$ per wk (out of $168 \mathrm{~h}$ ), which is a shockingly long duration. Infact there have been times when we have stayed on call every two days out of three (133 out of $168 \mathrm{~h}$ ). There are few other jobs which extract such long and strenuous working hours. The on call rooms (where ever they exist) leave a lot to be desired. The make shift bed, the uncomfortable conditions, the rats, the mosquitoes, the disturbing nurses (intravenous lines out and o.p.d. patients), the noisy servants and finally the patients' relatives hardly help to make the new arrivals' initial tenure pleasant and memorable.

Mukesh Sanklecha

doctormukesh@gmail.com

1 Department of Pediatrics, Bombay Hospital Institute of Medical Sciences, Mumbai, Maharashtra 400020, India
Apart from unsatisfactory working conditions, pay scales of residents are rather poor resulting in residents struggling to "eke out a living". Conditions are probably better in the northern states with better working conditions and much better pay scales (unfortunately MARD has fought a losing battle for central parity on several occasions). Hospital rules allow residents a maximum of ten days leave in the first 6 mo which, everybody will agree, is grossly inadequate, keeping in mind that two out of every three Sundays are spent by the residents on campus and on duty. Also one resident going on leave means doubling of the working hours of the co-resident with double suffering. Not only are the working conditions deplorable but even quarters provided to residents are overcrowded, poorly lit and poorly ventilated.

Such conditions lead not only to resident torture, but quality of work also suffers immediately and immensely. I vividly recall my resident days when decision taking seemed so difficult after a heavy on call and I struggled with simple problems. Clarity of the thought process was lost without adequate rest.

Though going through residency is essential and crucial for the learning process, the physical stress, the mental torture, working with a new group of people and with a totally new subject may lead to a lot of problems ranging from depression to even thoughts of quitting residency.

Already a raging controversy in the West, it is about time that the matter be looked into urgently including decrease in the number of working hours and making conditions more pleasant and working more enjoyable.

Conflict of Interest None.

Source of Funding None. 